\title{
Role of transdermal testosterone gel pre-treatment on IVF outcome: a prospective randomized controlled trial with active control
}

\author{
Neeta Singh, Padmashri Parimalam*, Sunesh Kumar, Perumal Vanamail
}

Department of Obstetrics and Gynecology, All India Institute of Medical Sciences, New Delhi, India

Received: 06 July 2021

Revised: 02 August 2021

Accepted: 03 August 2021

\section{*Correspondence:}

Dr. Padmashri Parimalam,

E-mail: ppadmashri@gmail.com

Copyright: ( ) the author(s), publisher and licensee Medip Academy. This is an open-access article distributed under the terms of the Creative Commons Attribution Non-Commercial License, which permits unrestricted non-commercial use, distribution, and reproduction in any medium, provided the original work is properly cited.

\section{ABSTRACT}

Background: Dealing with poor ovarian responders is the newest challenge for the present-day reproductive physicians. Androgens are said to increase pregnancy outcomes due to enhanced oocyte retrieval in poor responders. The aim of the study was to measure the effect of transdermal testosterone gel in women with unexplained poor ovarian response. Methods: It was a prospective randomized controlled trial with active control conducted at ART centre, department of obstetrics and gynaecology, AIIMS, New Delhi from August 2017-August 2018. Seventy women with previously failed IVF/ICSI who had $\leq 5$ oocyte retrieval in previous cycle having normal ovarian reserve with normal or low testosterone levels were randomized. Study arm $(\mathrm{N}=35)$ received testosterone gel pre-treatment whereas the control arm $(\mathrm{N}=35)$ received standard treatment. GnRH antagonist stimulation protocol was followed. The number of oocytes retrieved and pregnancy outcomes were studied.

Results: Of the 70 women in the study, the number of oocytes retrieved was significantly higher $(6.5 \pm 5.8$ vs $3.1 \pm 2.1$; $\mathrm{p}=0.002)$, cycle cancellation rate was lower (8.6\% vs $22.9 \%$; $=0.094)$, implantation rate $(8.2 \%$ vs $2.6 \% ; \mathrm{p}=0.228)$, clinical pregnancy, ongoing pregnancy, live birth rates $(14.7 \%$ vs $2.9 \%$; $=0.092)$ and take home baby rates $(17.6 \%$ vs $2.9 \% ; \mathrm{p}=0.049)$ were higher in testosterone group compared to controls. One woman in testosterone group developed mild OHSS.

Conclusions: The study shows that transdermal testosterone gel is found to improve oocyte retrieval significantly in unexpected poor responders, although there was not a significant improvement in pregnancy outcomes. Hence further studies are of utmost importance to establish the effectiveness of the gel.

Keywords: Testosterone, IVF, Androgen, Poor ovarian responder, Response

\section{INTRODUCTION}

Fertility rates are showing a declining trend and assisted reproductive technology plays an important role in catering to the reproductive needs of infertile population. ${ }^{1}$ Managing poor responders poses a very big challenge for the present-day reproductive physicians. Different techniques like changing the stimulation protocol, dual stimulation and using adjuvants like growth hormone, DHEA, testosterone are being tried to manage poor ovarian response. ${ }^{2}$ Among studies on poor responders, there are limited studies in women with unexpected poor ovarian response.

Frattarelli et al discovered a correlation between decreased serum testosterone levels and a poor IVF outcome. ${ }^{3}$ Androgens increase follicular recruitment and maturation by augmenting the action of FSH and IGF-1 through a rise in receptor expression. ${ }^{4}$ Short-term low dose testosterone and DHEA are being tried in poor responders due to this property to enhance the oocyte recovery rate and for a subsequent increase in pregnancy outcome. Studies on 
exogenous androgens show a positive effect on ovarian response and pregnancy outcome, however, are currently inconsistent. $^{2}$ Due to a limited number of trials in unexpected poor responders, we decided to conduct a randomized controlled trial in such women using low dose transdermal testosterone gel, given as pretreatment before IVF stimulation and to study the effect on oocyte retrieval and pregnancy outcome.

\section{METHODS}

It was a prospective randomized controlled trial.

\section{Sample size calculation}

According to the study done in South Korea by Kim et al, the number of oocytes retrieved after transdermal testosterone pretreatment was $5.4 \pm 1.9$ while $3.8 \pm 1.4$ oocytes were retrieved following standard treatment. ${ }^{5}$ Assuming the same rate of retrieval holds good in this study, a sample size of 35 in each group will detect significant difference between testosterone gel and standard with $90 \%$ power at $5 \%$ level of significance. Considering a dropout rate of $10 \%$, a total of 35 patients in each group were recruited.

This study was conducted at the Assisted Reproductive Technology Centre, department of obstetrics and gynecology, AIIMS, New Delhi from August 2017 to August 2018.

\section{Inclusion criteria}

Encompassed women with a previous one failed IVF/ICSI cycle satisfying the following criteria: those who had less than or equal to 5 oocytes retrieved in the previous cycle at maximum dose of stimulation and were $\leq 39$ years old, having $\mathrm{FSH} \leq 10$, BMI $\leq 30$ with any $\mathrm{AMH}$ and $\mathrm{AFC}$, having normal TSH, prolactin, hepatic and renal function, normal or low testosterone levels (reference range for normal total testosterone taken: 0.1-0.9 ng/ml), normal uterine cavity as assessed by hysteroscopy and 3D USG with none having taken any fertility medication like gonadotropins or clomiphene in the past 3 months.

\section{Exclusion criteria}

It consisted of women with known causes of decreased ovarian reserve like endometriosis grade 3 or higher, women with pre-existing comorbidities like uncontrolled diabetes, hypertension and other chronic diseases like chronic liver or kidney disease, women with known autoimmune disorders, abnormal parental karyotype and abnormal uterine cavity such as thin endometrium and severe adenomyosis. Computer generated random sequences were used for randomization. The study began after clearance from the Institute Ethics Committee of AIIMS. This study was registered with the Clinical Trials Registry of India.
Both the study and control groups received oral medication Norethisterone $5 \mathrm{mg}$ and estradiol valerate $1 \mathrm{mg}$ once daily from day 5 for a period of 21 days in the cycle before stimulation. Women in the study group were advised transdermal testosterone gel (1\%) (androgel from Besins Healthcare India Pvt Ltd) application from day 5 of starting pills till day 1 of menses. The gel was smeared using spatula at a dose of $12.5 \mathrm{mg}$ per day during bedtime, applied in thin layers on both the arms, and then allowed to evaporate. The women in control arm served as active controls and did not receive gel treatment. GnRH antagonist protocol was used for stimulation. Gonadotropins (recombinant FSH- Gonal F®, Merck Serono, Mumbai, India) were started from day 2 or 3 of the menstrual cycle depending on the patient profile, and continued until hCG trigger. Dose was decided according to the age, BMI, AFC and AMH of the patients. When a single follicle of $14 \mathrm{~mm}$ size was seen on USG, GnRH antagonist cetrotide (injection Cetrorelix ${ }^{\circledR}$, Merck Serono, Mumbai, India) $0.25 \mathrm{mg}$ subcutaneously was initiated to prevent premature LH surge and continued daily until hCG trigger. Doses of gonadotropins were modulated depending on the response. Recombinant hCG $250 \mu \mathrm{g}$ subcutaneous (Ovitrelle $\AA$; Merck Serono, Mumbai, India) was used as a trigger when at least two leading follicles were of $\geq 18 \mathrm{~mm}$ size.

After 34-36 hours of hCG trigger, oocyte retrieval was done and oocytes were graded according to maturity as grade 1 (metaphase 2), grade 2 (metaphase 1) and grade 3 (germinal vesicle) oocytes. IVF/ICSI was done according to indication. Embryos obtained were then graded according to maturity based on Istanbul criteria of embryological grading. ${ }^{6}$ Cleavage stage embryos are transferred on day 2 or day 3 of cycle. Blastocyst transfer was done at day 5 of cycle. Upto 4 cleavage stage embryos depending on the grade were transferred. Single embryo transfer was done if blastocysts were obtained. Surplus embryos were frozen. Both study and control groups received luteal phase support with $100 \mathrm{mg}$ of progesterone daily intramuscularly or natural micronized progesterone $400 \mathrm{mg}-600 \mathrm{mg}$ daily and estradiol valerate $2 \mathrm{mg}$ three times a day orally starting from the day of oocyte retrieval. Luteal phase support was continued for all women until the pregnancy was confirmed by serum $\beta$-hCG levels after embryo transfer in both the groups. Women with a positive pregnancy test further continued to receive routine luteal phase support at least until the 12th week of gestation. They were then followed till delivery and then discharged from the hospital. Pregnancy rates were then calculated.

\section{Outcome measures}

Primary outcome was to measure and compare the number of oocytes retrieved per IVF cycle in women in the study group versus control group. Secondary outcomes included measuring and comparing the following between the two groups: total dose and number of days of administration of gonadotropins, cycle cancellation rate (cycles which did not proceed to oocyte retrieval out of the total number of 
cycles), fertilization rate (percentage of eggs fertilized out of eggs inseminated or injected), cleavage rate (total number of day 3 embryos by total number of fertilized oocytes), number of good quality embryos, implantation rate (total number of gestational sacs divided by the total number of transferred embryos multiplied by 100), biochemical pregnancy rate (pregnancy detected by $\beta$-hCG measurement $>50$ IU/l but no gestational sac seen on transvaginal ultrasound), clinical pregnancy rate (defined as the presence of an intrauterine gestational sac with ultrasonographically detected fetal cardiac activity at 6 weeks of gestation. Multiple gestational sacs were counted as one clinical pregnancy. Rate was defined per cycle of treatment), ongoing pregnancy rate (pregnancy proceeding beyond the 12th gestational week per cycle of treatment) and live birth rate (any birth after 24 weeks gestation resulting in the delivery of a live infant calculated per cycle).

\section{Statistical analysis}

Data analysis was carried out using statistical software STATA version 12.0. Continuous variables were tested for normality of assumption using Kolmogorov Smirnov test. Descriptive statistics such as mean, standard deviation and range values were calculated for normally distributed data.
Comparison of mean values between the groups was carried out using student t-independent test. Categorical variables were expressed as frequency and percent values. Comparison of categorical variables was performed using $\chi^{2} /$ Fisher exact test. Primary outcomes were expressed as percent and with $95 \%$ confidence interval. Bivariate correlation analysis was carried out to see the linear association between oocytes retrieved and other variables such as age, AMH, AFC, basal FSH and testosterone levels. Post hoc power analysis was carried for the primary outcome for mean oocytes retrieved. For all statistical tests a two-sided probability of $\mathrm{p}<0.05$ was considered statistically significant.

\section{RESULTS}

A total of 80 women were screened for eligibility out of which 70 women were enrolled and randomized to testosterone arm $(\mathrm{N}=35)$ and control arm $(\mathrm{N}=35)$. All women were analyzed for primary outcomes. One of the women in the study group did not undergo embryo transfer and her embryos were frozen due to risk of OHSS as 35 oocytes were retrieved from her. Thus 34 patients were analyzed for pregnancy outcomes in the study group and 35 patients were analyzed in the control group (Figure 1).

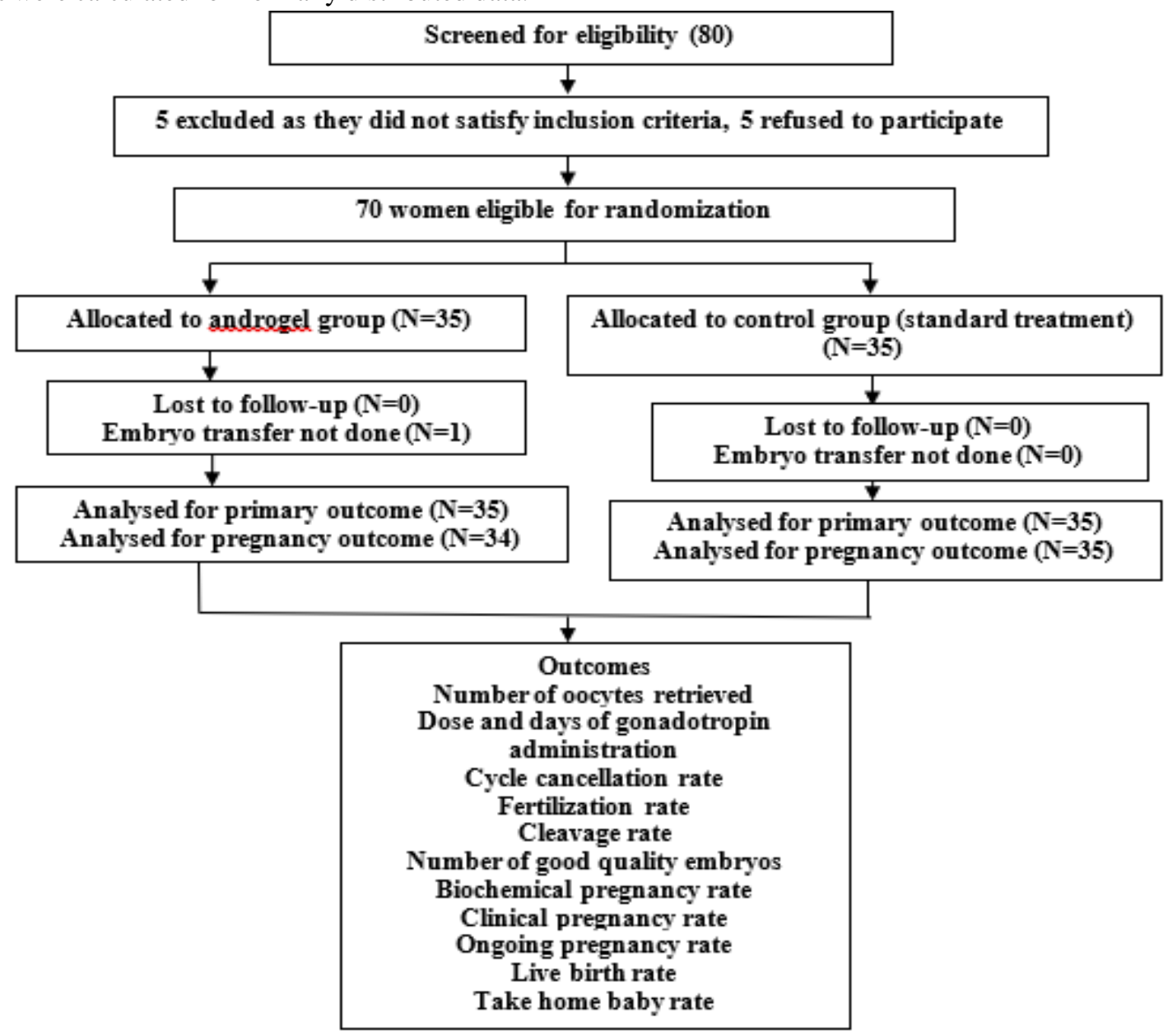

Figure 1: Consort flow of participants. 
All the baseline characteristics were comparable in both groups (Table 1). The etiological factors of infertility in the women recruited were those with tubal factor infertility, phenotype D PCOS (hypoandrogenic PCOS who also satisfied the inclusion criteria), endometriosis, unexplained and male factor infertility. One woman in the study arm had 35 oocytes retrieved due to which embryo transfer was deferred and one other woman in same arm developed early onset mild OHSS which was conservatively managed. No other adverse effects of the gel were observed. Mean \pm SD oocytes retrieved (6.5 \pm 5.8 vs $3.1 \pm 2.1 ; \mathrm{p}=0.002)$ and mean $\pm \mathrm{SD}$ grade 1 oocytes retrieved $(1.8 \pm 1.2$ vs $0.9 \pm 1.3 ; \mathrm{p}=0.001)$ were significantly higher in the testosterone group than the control group (Table 2). Bivariate correlation analysis revealed that there was a significant positive correlation between AFC and oocytes retrieved $(r=0.488 ; p=0.003)$. Power of the study, calculated by post-hoc analysis, for overall oocytes retrieved was $90 \%$. There was no difference in the mean \pm SD total dose and the number of days of gonadotropin administration between the groups (3218.7 \pm 671.4 vs $3178.6 \pm 645.1 ; p=0.799)$. There was no significant difference in cycle cancellation rate $(8.6 \%$ vs $22.9 \% ; \mathrm{p}=0.094)$, mean $\pm \mathrm{SD}$ fertilization rate $(67.1 \pm 20.1 \%$ vs $63.7 \pm 48.7 \% ; \mathrm{p}=0.738)$ or cleavage rate $(91.3 \pm 15.9 \%$ vs $86.6 \pm 30.2 \% ; \mathrm{p}=0.459)$ between the groups. The number of grade 1 embryos $(1.8 \pm 1.2$ vs $0.9 \pm 1.3 ; \mathrm{p}=0.006)$ was significantly higher in the testosterone group.

Biochemical pregnancies and miscarriages were nil in both groups. There was no statistically significant difference in the implantation rate $(8.2 \%$ vs $2.6 \% ; \mathrm{p}=0.228)$, clinical pregnancy rate $(14.7 \%$ vs $2.9 \%$; $=0.092)$, ongoing pregnancy rate $(14.7 \%$ vs $2.9 \% ; \mathrm{p}=0.092)$ and live birth rates $(14.7 \%$ vs $2.9 \%$; $=0.092)$ between the two groups. Pregnancy complications were not clinically significant in both the groups (Table 3). One patient in the study group had a twin pregnancy and thus the take home baby rate was significantly higher in the study group (17.6\% vs $2.9 \%$; $\mathrm{p}=0.049$ ). Embryo transfer rate was higher in the study group in comparison to the control group. So, the reason for the higher pregnancy rate in the study group could be because of the higher number of embryos transferred.

Table 1: Baseline characteristics.

\begin{tabular}{|c|c|c|c|}
\hline Characteristics & $\begin{array}{l}\text { Study group } \\
(\mathrm{N}=35)(\text { Mean } \pm \mathrm{SD})\end{array}$ & $\begin{array}{l}\text { Control group } \\
(\mathrm{N}=35)(\text { Mean } \pm \mathrm{SD})\end{array}$ & $P$ value \\
\hline Age (years) & $30.6 \pm 3.2$ & $32.1 \pm 3.5$ & $0.214 *$ \\
\hline BMI $\left(\mathrm{kg} / \mathrm{m}^{2}\right)$ & $24.3 \pm 2.7$ & $24.1 \pm 3.1$ & $0.805^{*}$ \\
\hline Duration of infertility (years) & $8.3 \pm 4.1$ & $8.3 \pm 3.8$ & $1.000 *$ \\
\hline AMH (ng/dl) & $4.3 \pm 3.7$ & $4.9 \pm 3.9$ & $0.493 *$ \\
\hline FSH (mIU/ml) & $6.2 \pm 1.9$ & $5.8 \pm 1.6$ & $0.339 *$ \\
\hline LH (mIU/ml) & $5.2 \pm 2.9$ & $5.0 \pm 1.5$ & $0.758^{*}$ \\
\hline Testosterone (ng/dl) & $0.26 \pm 0.07$ & $0.26 \pm 0.06$ & $0.723 *$ \\
\hline AFC & $13.1 \pm 5.6$ & $13.2 \pm 4.5$ & $0.926^{*}$ \\
\hline ET on day of trigger (mm) & $9.0 \pm 1.0$ & $8.6 \pm 1.2$ & $0.199 *$ \\
\hline \multicolumn{4}{|l|}{ Type of procedure } \\
\hline IVF & $27(77.2)$ & $25(71.4)$ & \multirow{2}{*}{$0.584 * *$} \\
\hline ICSI & $8(22.8)$ & $10(28.6)$ & \\
\hline \multicolumn{4}{|l|}{ Etiology of infertility } \\
\hline Tubal & $13(37.1)$ & $12(34.3)$ & \multirow{4}{*}{$0.993 * *$} \\
\hline Type D PCOS & $7(20.0)$ & $7(20.0)$ & \\
\hline Endometriosis & $2(5.7)$ & $3(8.6)$ & \\
\hline Unexplained & $8(22.9)$ & $8(22.9)$ & \\
\hline \multicolumn{4}{|c|}{ History of genital tuberculosis } \\
\hline Present & $12(34.3)$ & $12(34.3)$ & \multirow{2}{*}{$0.599 * *$} \\
\hline Absent & $23(65.7)$ & $23(65.7)$ & \\
\hline
\end{tabular}

Note: $* \mathrm{P}$ values calculated by $\chi^{2}$-test, $* * \mathrm{P}$ values calculated by $\mathrm{t}$-test.

Table 2: Outcomes.

\begin{tabular}{|c|c|c|c|}
\hline Characteristics & $\begin{array}{l}\text { Study group } \\
(\mathrm{N}=35)(\text { Mean } \pm \mathrm{SD})\end{array}$ & $\begin{array}{l}\text { Control group } \\
(\mathrm{N}=35)(\text { Mean } \pm \text { SD })\end{array}$ & P value \\
\hline $\begin{array}{l}\text { Total dose of gonadotropins } \\
\text { (IU) }\end{array}$ & $30.6 \pm 3.2$ & $32.1 \pm 3.5$ & $0.214^{*}$ \\
\hline $\begin{array}{l}\text { Number of days of } \\
\text { gonadotropins }\end{array}$ & $24.3 \pm 2.7$ & $24.1 \pm 3.1$ & $0.805^{*}$ \\
\hline Number of days of antagonist & $8.3 \pm 4.1$ & $8.3 \pm 3.8$ & $1.000^{*}$ \\
\hline
\end{tabular}




\begin{tabular}{|c|c|c|c|c|c|}
\hline Characteristics & \multicolumn{2}{|c|}{$\begin{array}{l}\text { Study group } \\
(\mathbf{N}=35)(\text { Mean } \pm \text { SD })\end{array}$} & \multicolumn{2}{|c|}{$\begin{array}{l}\text { Control group } \\
(\mathrm{N}=35)(\text { Mean } \pm \text { SD })\end{array}$} & P value \\
\hline Number of oocytes retrieved & \multicolumn{2}{|l|}{$4.3 \pm 3.7$} & \multicolumn{2}{|l|}{$4.9 \pm 3.9$} & $0.493^{*}$ \\
\hline Grade 1 oocytes & \multicolumn{2}{|l|}{$6.2 \pm 1.9$} & \multicolumn{2}{|l|}{$5.8 \pm 1.6$} & $0.339 *$ \\
\hline Grade 2 oocytes & \multicolumn{2}{|l|}{$5.2 \pm 2.9$} & \multicolumn{2}{|l|}{$5.0 \pm 1.5$} & $0.758^{*}$ \\
\hline Grade 3 oocytes & \multicolumn{2}{|c|}{$0.26 \pm 0.07$} & \multicolumn{2}{|c|}{$0.26 \pm 0.06$} & $0.723^{*}$ \\
\hline Number fertilized & \multicolumn{2}{|l|}{$13.1 \pm 5.6$} & \multicolumn{2}{|l|}{$13.2 \pm 4.5$} & $0.926^{*}$ \\
\hline Fertilization rate (\%) & \multicolumn{2}{|l|}{$9.0 \pm 1.0$} & \multicolumn{2}{|l|}{$8.6 \pm 1.2$} & $0.199 *$ \\
\hline \multicolumn{6}{|l|}{ Number cleaved } \\
\hline Cleavage rate $(\%)$ & \multicolumn{2}{|l|}{$27(77.2)$} & \multicolumn{2}{|l|}{$25(71.4)$} & \multirow{2}{*}{$0.584 * *$} \\
\hline Grade 1 embryos & \multicolumn{2}{|l|}{$8(22.8)$} & \multicolumn{2}{|l|}{$10(28.6)$} & \\
\hline \multicolumn{6}{|l|}{ Grade 2 embryos } \\
\hline Grade 3 embryos & \multicolumn{2}{|l|}{$13(37.1)$} & \multicolumn{2}{|l|}{$12(34.3)$} & \multirow{5}{*}{0.094} \\
\hline \multirow{2}{*}{ Oucomes } & \multicolumn{2}{|c|}{ Study group $(\mathrm{N}=35)$} & \multicolumn{2}{|c|}{ Control group $(\mathrm{N}=35)$} & \\
\hline & Rate & $95 \% \mathrm{CI}$ & Rate & $95 \% \mathrm{CI}$ & \\
\hline Cycle cancellation rate (\%) & $3(8.6)$ & $0,17.8$ & $8(22.9)$ & $8.9,36.8$ & \\
\hline Oucomes & \multicolumn{2}{|c|}{ Study group $(\mathrm{N}=34)($ Mean $\pm \mathrm{SD})$} & \multicolumn{2}{|c|}{ Control group $(\mathrm{N}=35)($ Mean $\pm \mathrm{SD})$} & \\
\hline Number of embryos transferred & \multicolumn{2}{|l|}{$2.1 \pm 1.2$} & \multicolumn{2}{|l|}{$1.1 \pm 1.2$} & 0.001 \\
\hline $\begin{array}{l}\text { Number of cleavage stage } \\
\text { embryos transferred }\end{array}$ & \multicolumn{2}{|l|}{$1.9 \pm 1.3$} & \multicolumn{2}{|l|}{$0.9 \pm 1.1$} & 0.001 \\
\hline $\begin{array}{l}\text { Number of blastocysts } \\
\text { transferred }\end{array}$ & $0.1 \pm 0.6$ & & $0.2 \pm 0.8$ & & 0.616 \\
\hline Number of embryos frozen & $0.4 \pm 1.4$ & & $0.1 \pm 0.5$ & & 0.205 \\
\hline Outcomes & Study gro & $=35)$ & Control g & 35) & \\
\hline Otconites & Rate & $95 \% \mathrm{CI}$ & Rate & $95 \% \mathrm{CI}$ & \\
\hline Implantation rate (\%) & 8.2 & $1.9,14.5$ & 2.6 & $0,8.4$ & 0.228 \\
\hline Clinical pregnancy rate $(\%)$ & $5(14.7)$ & $2.8,26.6$ & $1(2.9)$ & $0,8.4$ & 0.092 \\
\hline Ongoing pregnancy rate (\%) & $5(14.7)$ & $2.8,26.6$ & $1(2.9)$ & $0,8.4$ & 0.092 \\
\hline Live birth rate (\%) & $5(14.7)$ & $2.8,26.6$ & $1(2.9)$ & $0,8.4$ & 0.092 \\
\hline Take home baby rate (\%) & 17.6 & $4.8,30.5$ & 2.9 & $0,8.4$ & 0.049 \\
\hline
\end{tabular}

Table 3: Pregnancy complications.

\begin{tabular}{|c|c|c|c|}
\hline Pregnancy complications & Study group & $\begin{array}{l}\text { Control } \\
\text { group }\end{array}$ & Details \\
\hline $\begin{array}{l}\text { Hypertensive disorders of } \\
\text { pregnancy }\end{array}$ & 1 & 1 & $\begin{array}{l}\text { One patient in the study group developed severe } \\
\text { pre-eclampsia at } 37 \text { weeks and the patient in the } \\
\text { control group developed gestational hypertension. }\end{array}$ \\
\hline $\begin{array}{l}\text { Intrahepatic cholestasis of } \\
\text { pregnancy }\end{array}$ & 1 & 0 & $\begin{array}{l}\text { One patient in the study group required } \\
\text { termination at } 37 \text { weeks due to intrahepatic } \\
\text { cholestasis of pregnancy. }\end{array}$ \\
\hline Pre-term labour & 1 & 0 & $\begin{array}{l}\text { One patient in the study group required rescue } \\
\text { cerclage at } 19 \text { weeks and later delivered preterm } \\
\text { at } 28 \text { weeks }\end{array}$ \\
\hline Congenital anomalies & 1 & 0 & $\begin{array}{l}\text { One patient in the study group had unilateral } \\
\text { congenital talipes equinus varus (CTEV) in the } \\
\text { baby not associated with any other anomaly. }\end{array}$ \\
\hline Neonatal complications & 1 & 0 & $\begin{array}{l}\text { The baby of the patient who had preterm labour } \\
\text { had hyaline membrane disease, required surfactant } \\
\text { and delayed adaptation. Was discharged on } 98^{\text {th }} \\
\text { day from hospital uneventfully. }\end{array}$ \\
\hline
\end{tabular}

\section{DISCUSSION}

In this study, we studied the effect of transdermal testosterone on poor responders with normal ovarian reserve having normal or low testosterone levels. It demonstrated a significant increase in the number of oocytes retrieved, take home baby rate and a nonsignificant increase in pregnancy rates following 
application of testosterone gel before stimulation. Androgen treatment, either in the form of DHEA or transdermal testosterone, has been studied by many in literature. Androgens were first used in clinical setting by Casson et al and he identified that DHEA induces temporary accumulation of intra ovarian androgens. ${ }^{7}$ Frattarelli et al discovered that decreased testosterone levels (day $3<20 \mathrm{ng} / \mathrm{dl}$ ) correlates with poor IVF success rates. $^{3}$ Massin et al reported that testosterone gel application caused a significant rise in plasma levels of testosterone but did not improve antral follicular count, numbers of pre-ovulatory follicles, total and mature oocyte numbers. ${ }^{8}$

In 2009, the study by Fabregues et al showed that pretreatment with transdermal testosterone results in an enhanced follicular response in comparison to using a high dose gonadotropin and mini dose GnRH agonist protocols in women with previous poor response. This effect was observed only in women with normal basal FSH and not in those with elevated basal FSH. ${ }^{9}$ This is the only trial evaluating the role of transdermal testosterone in unexpected poor responders. In 2011, Kim et al conducted a randomized controlled trial in 110 poor responders and reported an increase in the number of oocytes retrieved and pregnancy rates in the testosterone group. ${ }^{5}$ In a similar trial in 2016, Bosdou et al reported no significant difference in the number of cumulus oocyte complexes retrieved, fertilization rates and live birth rates between the testosterone and control groups. ${ }^{10}$ One other trial in 2017 by HT Doan et al showed an increase in the number of oocytes retrieved, number of embryos, pregnancy rate, and embryo implantation rate in testosterone gel group compared to control group. ${ }^{11}$

In this study we included women with normal ovarian reserve with a previous poor ovarian response. While recruiting women in the trial we observed that there were certain women, who were previously diagnosed with PCOS by modified Rotterdam criteria, also had normal or low serum testosterone levels. These women also satisfied our inclusion criteria. We did a literature review and identified that these women fall under the category 'hypoandrogenic PCOS' (type D PCOS). Gleicher et al had conducted a retrospective cohort study on type D PCOS in which DHEA supplementation was given in women with high AMH (>75th quartile of age specific values) with low or normal testosterone for a period of 6 8 weeks before stimulation. ${ }^{12}$ This phenotype represents women who had expressed a non-obese hyperandrogenic PCOS phenotype at a younger age but as age advanced, the testosterone levels decreased disproportionately compared to $\mathrm{AMH}$ creating an environment with low testosterone disadvantageous to folliculogenesis and fertility. Thus, testosterone supplementation in such women helps restore their follicular response and helps improve IVF outcome. In this study, these women also had a response to testosterone supplementation. But the significance of this finding is unknown and there is a need for trials focusing on these women.
The limitations of this study were, Bologna criteria for poor ovarian response is not used due to which there can be difficulty in generalizing the results to poor responders satisfying the criteria. The sample size was not large enough to detect significant difference in pregnancy outcomes.

\section{CONCLUSION}

This study shows that testosterone gel pretreatment is useful in women with unexpected poor ovarian response in the previous cycle to improve IVF outcome, and also opens the need for research on androgen supplementation in women with type D PCOS with poor ovarian response. It can be inferred that testosterone increases FSH receptor sensitivity and is potentially useful in women with an unexpected poor ovarian response in previous cycle. Testosterone can also be helpful in women with type D PCOS, however it mandates the need for more systematically conducted trials on androgen supplementation in type D PCOS women to confirm the same. The need for large multicenter trials to evaluate the role of testosterone in unexpected poor responders on pregnancy outcome stands inevitable.

\section{ACKNOWLEDGMENTS}

Authors would like to thank Besins healthcare India Pvt Ltd for offering androgel sachets to study participants and the staff of IVF lab for offering their support.

Funding: Androgel sachets were given for study participants free of cost by Besins healthcare India Pvt Ltd. No other funding sources

Conflict of interest: None declared

Ethical approval: The study was approved by the Institutional Ethics Committee

\section{REFERENCES}

1. Vollset SE, Goren E, Yuan CW, Cao J, Smith AE, Hsiao T, Bisignano C, et al. Fertility, mortality, migration, and population scenarios for 195 countries and territories from 2017 to 2100: a forecasting analysis for the Global Burden of Disease Study. Lancet. 2020;396(10258):1285-306.

2. Zhang Y, Zhang C, Shu J, Guo J, Chang HM, Leung $\mathrm{PCK}$, et al. Adjuvant treatment strategies in ovarian stimulation for poor responders undergoing IVF: a systematic review and network meta-analysis. Hum Reprod Update. 2020;26(2):247-63.

3. Frattarelli JL, Gerber MD. Basal and cycle androgen levels correlate with in vitro fertilization stimulation parameters but do not predict pregnancy outcome. Fertil Steril. 2006;86(1):51-7.

4. Gervasio CG, Bernuci MP, Silva MF, Rosa SAC. The role of androgen hormones in early follicular development. ISRN Obstet Gynecol. 2014;2014:818010. 
5. Kim CH, Howles CM, Lee HA. The effect of transdermal testosterone gel pretreatment on controlled ovarian stimulation and IVF outcome in low responders. Fertil Steril. 2011;95(2):679-83.

6. Alpha Scientists in Reproductive Medicine and ESHRE Special Interest Group of Embryology. The Istanbul consensus workshop on embryo assessment: proceedings of an expert meeting. Hum Reprod. 2011;26(6):1270-83.

7. Casson PR, Lindsay MS, Pisarska MD, Carson SA, Buster JE. Dehydroepiandrosterone supplementation augments ovarian stimulation in poor responders: a case series. Hum Reprod. 2000;15(10):2129-32.

8. Massin N, Durnerin I, Coussieu C, Fontaine J, Wolf JP, Hugues JN. Effects of transdermal testosterone application on the ovarian response to $\mathrm{FSH}$ in poor responders undergoing assisted reproduction technique--a prospective, randomized, double-blind study. Hum Reprod. 2006;21(5):1204-11.

9. Fabregues F, Penarrubia J, Creus M, Manau D, Casals G, Carmona F, et al. Transdermal testosterone may improve ovarian response to gonadotrophins in lowresponder IVF patients: a randomized, clinical trial. Hum Reprod. 2009;24(2):349-59.

10. Bosdou JK, Venetis CA, Dafopoulos K, Zepiridis L, Chatzimeletiou K, Anifandis G, et al. Transdermal testosterone pretreatment in poor responders undergoing ICSI: a randomized clinical trial. Hum Reprod. 2016;31(5):977-85.

11. Doan HT, Quan LH, Nguyen TT. The effectiveness of transdermal testosterone gel 1\% (androgel) for poor responders undergoing in vitro fertilization. Gynecol Endocrinol. 2017;33(12):977-9.

12. Gleicher N, Kushnir VA, Darmon SK, Wang Q, Zhang L, Albertini DF, Barad DH. Suspected ontogeny of a recently described hypo-androgenic PCOS-like phenotype with advancing age. Endocrine. 2018;59(3):661-76.

Cite this article as: Singh N, Parimalam P, Kumar S, Vanamail P. Role of transdermal testosterone gel pretreatment on IVF outcome: a prospective randomized controlled trial with active control. Int J Reprod Contracept Obstet Gynecol 2021;10:3509-15. 